\title{
Production of red mold rice using a modified Nagata type koji maker
}

\author{
Chiu-Hsia Chiu • Kuang-Huei Ni • Yuan-Kuang Guu • \\ Tzu-Ming Pan
}

Received: 21 February 2006 /Revised: 3 April 2006 / Accepted: 5 April 2006 / Published online: 7 October 2006

(C) Springer-Verlag 2006

\begin{abstract}
In this research, a commercial koji maker with a rotary perforated bed of 5-m diameter was modified for red mold rice production. Monascus purpureus BCRC 31499 was selected for its high production capacities of monacolin $\mathrm{K}$ and red pigment. The selected strain was first cultivated in a 120-1 submerged type fermentor at $34^{\circ} \mathrm{C}$ and $2 \mathrm{vvm}$ aeration rate with $60 \mathrm{rpm}$ agitation for 5 days using $20 \%$ liquefied rice porridge as carbon source. The high concentration red mold rice broth $(>3.5 \mathrm{~g} / \mathrm{ml})$ was harvested for inocula and well mixed with cooked rice to an initial concentration of $2 \% \mathrm{v} / \mathrm{w}$. The inoculated cooked rice then was directed into the modified koji maker, in which temperature and humidity profiles were kept at varied levels at different stages, respectively. Air was circulated to remove fermentation heat while the perforated bed rotated slowly for providing mild agitation. Lag phase of the Monascus sp. in the modified koji maker was determined to be $16 \mathrm{~h}$ by the time the koji temperature raised rapidly. Water was added
\end{abstract}

\footnotetext{
C.-H. Chiu · T.-M. Pan $(\bowtie)$

Institute of Microbiology and Biochemistry,

National Taiwan University,

1, Sec. 4, Roosevelt Road,

106 Taipei, Taiwan

e-mail: tmpan@ntu.edu.tw

K.-H. Ni

Taiwan Tobacco and Liquor Corp.,

Pingtung, 912 Taiwan

C.-H. Chiu • Y.-K. Guu ( $\bowtie)$

National Pingtung University of Science and Technology,

1 Shuefu Road, Pingtung,

912 Taiwan, Republic of China

e-mail: ykguu@mail.npust.edu.tw
}

into the koji bed by a water curtain at the 36th hour to keep the moisture content of the rice koji at $50 \%$ or above. At the final stage, temperature was adjusted to $34^{\circ} \mathrm{C}$ to direct red pigment production. After 7 days, 1,200-kg high quality red mold rice was harvested per batch. Labor costs, space, and fermentation time were reduced tremendously compared with those made by traditional methods.

\section{Introduction}

Red mold rice (also known as red fermented rice or red yeast rice), produced from solid-state fermentation of cooked rice with Monascus sp., contains many high value substances, such as monacolin $\mathrm{K}, \gamma$-aminobutyric acid (GABA), natural red pigment, and other unidentified active components (Aniya et al. 2000; Blanc et al. 1995; Su et al. 2003). These components are the secondary metabolites of fermentation and are medically proven to possess anticholesterol, anticarcinogenic activities (Endo 1979, 1980; Hawksworth and Pitt 1983; Lee et al. 2005), and antifatigue activities (Wang et al. 2005). The Chinese ancient pharmacopoeia, Ben Tsao Gum Mu, indicates the use of red mold rice to promote the health of the cardiovascular systems (Kao 1997; Su 2001). Red mold rice is used in many Chinese processed foods and is used for red color enhancement and nutroceutical supplements at least for more than thousands of years. However, the formal written records were not unveiled until two pharmacopoeias were published in the Post-Han and Yuan Dynasties, respectively, which first described the medicinal functions of red mold rice (Bau 1996; Su 2001). In ca 1590, another pharmacopoeia was published and released describing the method for making red mold rice (Bau 1996). This method 


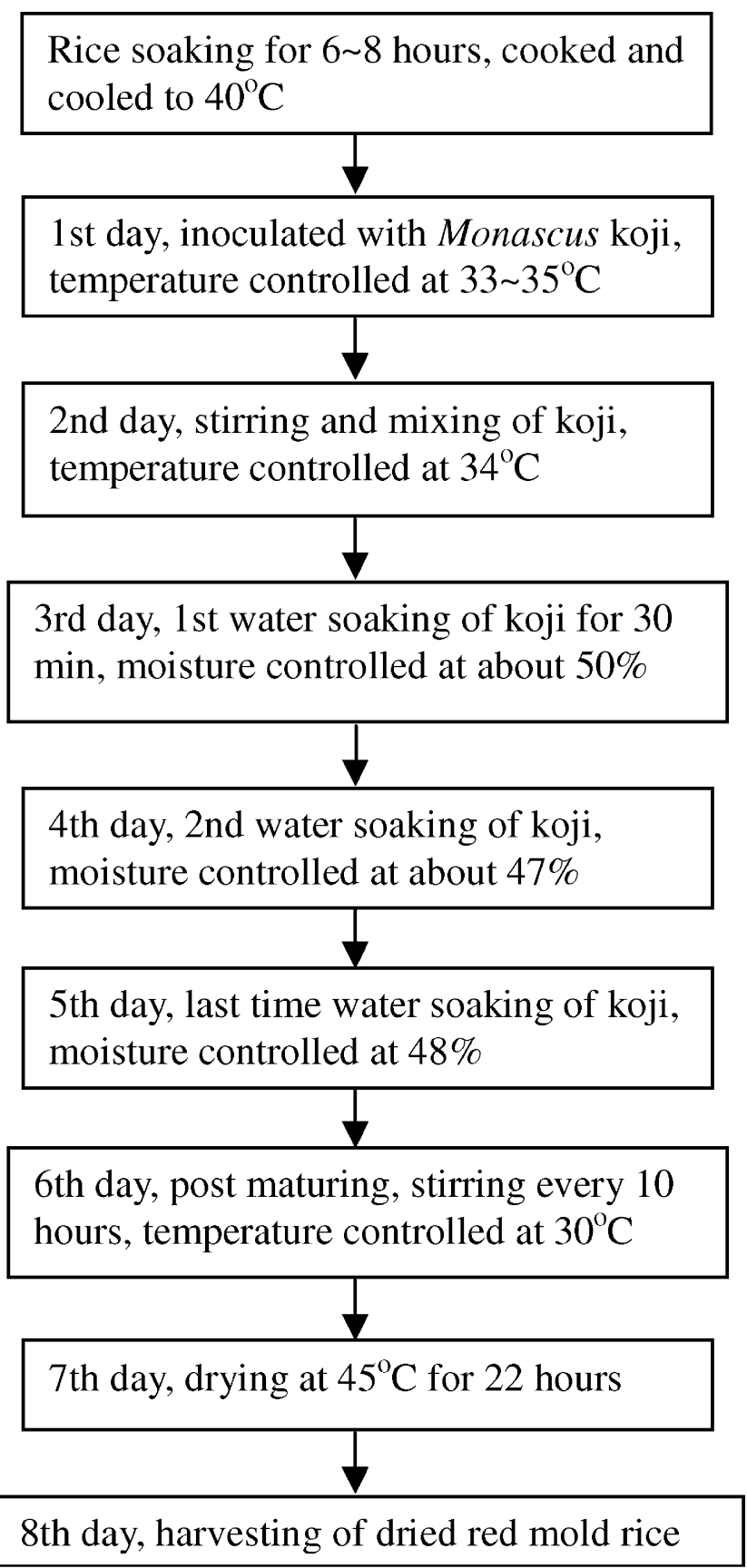

Fig. 1 Red mold rice production procedure by traditional process

has ever since been adopted as the standard fermentation process until recent years, as shown in Fig. 1.

In the traditional process, for easy control of aeration and removal of fermentation heat, the inoculated cooked rice is put in a round shallow bamboo tray about $5-6 \mathrm{~cm}$ in depth. Trays are stacked in shelves in a fermentation room. Agitation with hands is needed to flip over the bottom part of the rice koji and removing fermentation heat. During fermentation, each tray is taken out at least three times from the room and soaked in water to maintain the proper moisture content of the rice koji. However, the traditional method needs a large space for aerobic solid-state fermentation, high labor costs for koji agitation by hands and water soaking, and a long process time. Fermentation is easily contaminated by the open environmental factors, which always results in inconsistent and unsatisfactory quality (Bau 1996; Su 2001).

Microbiological studies of red molds was first conducted in 1884 by van Tieghem, a French microbiologist, and were categorized as the genus Monascaceae (Huang 1985; Su et al. 1970). Many species with similar red fungal filamentous appearance and physiological characteristics were isolated and named after different kinds of products since then. The most widely used red mold species in Taiwan was first named Monascus anka in 1931 by two Japanese, Misawa and Sato (Su et al. 1970). This finding led to the use of pure culture in commercial production of red mold rice. However, due to the strict limit of the "Monopoly Law for Production and Selling of Tobacco and Liquor," commercial production of red mold rice was only authorized to Taiwan Tobacco and Liquor Monopoly Corporation. Most researches for red mold rice production were only conducted in its affiliated Taiwan Wine Research Institute (TWRI), including species selection and process modification.

Literature survey on red mold rice production in a closed environment using a koji maker shows no successful cases. Lin and his associates in TWRI tried it with a pilot scale $(50 \mathrm{~kg}$ in capacity) Nagata type rotary bed solid-state fermentor and ended up with unsatisfactory results (Lin 1982a,b, 1987). The result was attributed to the difficulties of water addition and fermentation heat removal in the site. Since then, no further studies had been conducted. On the other hands, reports on microbial strains used in red mold rice production and functional properties of metabolites were easily found (Endo 1980; Hawksworth and Pitt 1983; Lizuka and Lin 1980). Most of these works focused on the production capacities of monacolin, pigment, GABA, etc., and their applications as dietary supplements in healthy foods.

Twenty nine Monascus strains have been named and found possessing various production capacities of monacolin K, GABA, flavonoids, citrinin and red pigment, etc., as their primary and secondary metabolites, although citrinin is usually regarded as a hazardous factor to health. Among these strains, Monascus purpureus, M. anka, and Monascus ruber are the most often used for research and industrial production of red mold rice. However, their capacities for producing monacolin $\mathrm{K}, \mathrm{GABA}$, and red pigments are the major concerns (Su 2001).

In the mid-1950s, mechanization on koji production was just started in Japan. A Nagata type rotary bed koji maker (as shown in Fig. 2) was developed for making rice, soybean, and wheat koji for sake (Japanese rice wine) or soy sauce production using Aspergillus sp. as cultures. Major components of the rotary bed koji maker are a round 


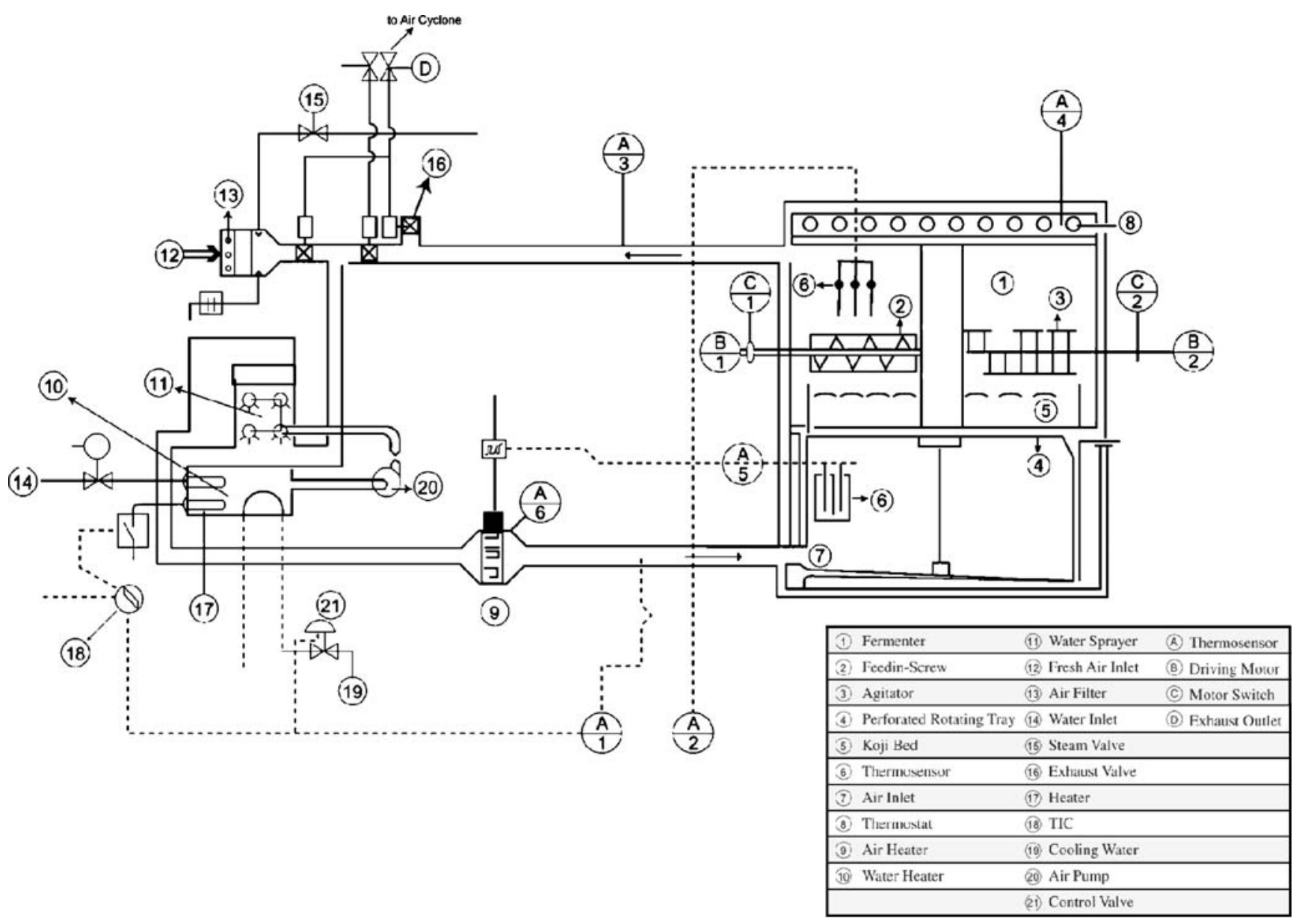

Fig. 2 The Nagata type large scale koji maker (Source: Lin 1987)

bed with at least $30 \mathrm{~cm}$ in depth and a perforated bottom plate for up-flow aeration; a set of adjustable speed mixer for plowing up rice koji during fermentation for assisting aeration, heat removal, and preventing koji from agglomeration; and a set of screw for cooked rice feed-in and koji discharge. Aeration system includes an air sterilizer and humidifier before charging into the bed, and a cyclone separator for the exhausted air. Temperature and humidity sensors are inserted for monitoring and control.

However, this Nagata type koji maker was originally designed for making koji with Aspergillus sp., which is physiologically and morphologically different from Monascus sp., especially on the aspects of moisture need and temperature rising speed of rice koji during solid-state fermentation. Therefore, modification for mass production of red mold rice in a more hygienic and controllable condition with mechanized koji making facilities became the motivation of this research. Controls of rice koji moisture content and fermentation temperature, and hence, modification of the koji maker, are definitely the cores of this research. The ultimate goals are to develop an optimal process for red mold rice mass production with high and consistent quality and low cost to meet the healthy food market demands.

\section{Materials and methods}

Microbial strain

M. purpureus BCRC 31499 was bought from Bioresources Collection and Research Center, Food Industry Research and Development Institute, Hsinchu, Taiwan.

\section{Media and substrates}

Indica rice medium was a mixture of Indica rice powder, $100 \mathrm{~g}, \mathrm{KH}_{2} \mathrm{PO}_{4}, 0.5 \mathrm{~g}$, monosodium glutamate (MSG), $1.5 \mathrm{~g}$, and lactic acid, $2 \mathrm{ml}$, in $850-\mathrm{ml}$ deionized water. Bread koji medium applied steamed white bread as raw material. Indica rice powder, $15 \mathrm{~kg}, \mathrm{MSG}, 110 \mathrm{~g}, \mathrm{KH}_{2} \mathrm{PO}_{4}$, $30 \mathrm{~g}$, and $\mathrm{CaHPO}_{4}, 15 \mathrm{~g}$, were liquefied and dissolved in 65-1 water as liquid culture medium for the 120-1 submerged 
fermentor. Cooked Indica rice was used for red mold rice mass production.

Reagents and materials

All chemical reagents were of reagent grade. Indica rice was of local variety, $90 \%$ polished with $74 \%$ starch value. Novo Termamyl (Novo, South Carolina, USA) was used as a liquefaction enzyme.

\section{Equipment}

Rice cooker with a capacity of $1,000 \mathrm{~kg}$ was capable of cooking rice with steam in $30 \mathrm{~min}$ and cooling rice from 100 to $30^{\circ} \mathrm{C}$ in $5 \mathrm{~min}$ (Miaoli Machine Shop, Miaoli, Taiwan). Submerged type fermentor for the production of inocula was 1201 with agitation, air aseptic, and temperature control systems. Nagata type koji maker containing a rotary bed with a capacity of $1,500 \mathrm{~kg}$ as shown in Fig. 2 was applied as a solid state fermentor for mass production (Agro-Industrial Machine, Chiayi, Taiwan). This fermentor was modified with different water-addition and temperature-control systems for application on red mold rice mass production.

Liquefaction methods and inocula used

In the 120-1 submerged type fermentor, $15-\mathrm{kg}$ rice powder was added to $65-1$ water and heated to $121^{\circ} \mathrm{C}$ for $50 \mathrm{~min}$. Lactic acid or Novo Termamyl was used as liquefaction agent and added into the medium (described below). Bread koji of $120 \mathrm{~g}$ or $2 \%(\mathrm{v} / \mathrm{w})$ liquefied rice powder culture was inoculated when medium temperature was lowered to $39^{\circ} \mathrm{C}$. Agitation at $60 \mathrm{rpm}$ and aeration of aseptic air at $2 \mathrm{vvm}$ were maintained during the cultivation period.
Six kinds of liquefaction methods were used in this study: (A) $2 \%(\mathrm{v} / \mathrm{w})$ lactic acid was used as liquefaction agent and $2 \%(\mathrm{v} / \mathrm{w})$ liquefied rice powder culture was used as inocula; (B) $0.2 \%(\mathrm{v} / \mathrm{w})$ Termamyl was added at $85^{\circ} \mathrm{C}$ and heated to $121^{\circ} \mathrm{C}$ for $50 \mathrm{~min}$ during liquefaction and $2 \%(\mathrm{v} / \mathrm{w})$ liquefied rice powder culture was used as inocula; (C) $0.1 \%(\mathrm{v} / \mathrm{w})$ Termamyl was added at $85^{\circ} \mathrm{C}$ and heated to $121^{\circ} \mathrm{C}$ for $50 \mathrm{~min}$, then, another $0.1 \%(\mathrm{v} / \mathrm{w})$ Termamyl was boosted when temperature was cooled down to $90^{\circ} \mathrm{C}$ during liquefaction and $2 \%(\mathrm{v} / \mathrm{w})$ liquefied rice powder culture was used as inocula; (D) $2 \%(\mathrm{v} / \mathrm{w})$ lactic acid was used as liquefaction agent and bread koji, $120 \mathrm{~g}$, was used as inocula; (E) $0.2 \%(\mathrm{v} / \mathrm{w})$ Termamyl was added at $85^{\circ} \mathrm{C}$ and heated to $121^{\circ} \mathrm{C}$ for $50 \mathrm{~min}$ and bread koji, $120 \mathrm{~g}$, was used as inocula; (F) $0.1 \%(\mathrm{v} / \mathrm{w})$ Termamyl was added at $85^{\circ} \mathrm{C}$ and heated to $121^{\circ} \mathrm{C}$ for $50 \mathrm{~min}$, then another $0.1 \%(\mathrm{v} / \mathrm{w})$ Termamyl was boosted when temperature was cooled down to $90^{\circ} \mathrm{C}$ during liquefaction and bread koji, $120 \mathrm{~g}$, was used as inocula.

\section{Analysis}

Red pigment, $\mathrm{pH}$ value, activity of glucoamylase, specific viscosity, and total acidity of red mold rice were analyzed based on the standard methods of TWRI (Anonymous 1994). Monacolin $\mathrm{K}$ and citrinin were analyzed following the methods developed by Hsieh and Pan (Hsieh and Pan 2002).

\section{Results}

Preparations of high concentration liquid culture

Viscosity of the porridge-like medium in liquid culture preparation will be lifted as increasing the concentration of rice porridge, which, in turn, will retard the growth of

Table 1 High concentration liquid koji inocula cultivated for 5 days

\begin{tabular}{|c|c|c|c|c|c|c|}
\hline Methods & Cell conc\% $\%(w / v)$ & $\mathrm{pH}$ value & Total acids (ml) & End point volume (1) & $\begin{array}{l}\text { Residual sugars } \\
(\mathrm{g} / 100 \mathrm{ml})\end{array}$ & Spec visc ${ }^{a}$ \\
\hline$A^{b}$ & $3.59 \pm 0.70(b)$ & $4.59 \pm 0.44(b)$ & $40.5 \pm 1.5(\mathrm{ab})$ & $49.5 \pm 3.9(\mathrm{~cd})$ & $3.17 \pm 0.44(\mathrm{a})$ & $3.90 \pm 0.38(a)$ \\
\hline $\mathrm{B}^{\mathrm{b}}$ & $3.78 \pm 0.85(\mathrm{ab})$ & $5.30 \pm 0.32(\mathrm{a})$ & $34.4 \pm 2.4(\mathrm{~b})$ & $59.0 \pm 2.3(\mathrm{~b})$ & $2.51 \pm 0.45(\mathrm{ab})$ & $2.90 \pm 0.12(\mathrm{abc})$ \\
\hline $\mathrm{C}^{\mathrm{b}}$ & $4.44 \pm 0.43(\mathrm{ab})$ & $5.37 \pm 0.44(\mathrm{a})$ & $34.2 \pm 1.3(\mathrm{~b})$ & $70.0 \pm 4.5(\mathrm{a})$ & $1.50 \pm 0.69(\mathrm{ab})$ & $1.50 \pm 0.06(\mathrm{c})$ \\
\hline $\mathrm{D}^{\mathrm{c}}$ & $4.32 \pm 0.20(\mathrm{ab})$ & $4.51 \pm 0.06(b)$ & $42.4 \pm 1.4(\mathrm{a})$ & $43.0 \pm 4.5(\mathrm{~d})$ & $3.00 \pm 0.34(\mathrm{a})$ & $3.60 \pm 0.25(\mathrm{ab})$ \\
\hline$E^{c}$ & $4.63 \pm 0.12(a b)$ & $5.29 \pm 0.13(\mathrm{a})$ & $34.7 \pm 1.1(\mathrm{~b})$ & $56.0 \pm 4.4(\mathrm{bc})$ & $1.72 \pm 0.33(\mathrm{ab})$ & $2.20 \pm 0.69(\mathrm{bc})$ \\
\hline $\mathrm{F}^{\mathrm{c}}$ & $4.86 \pm 0.27(\mathrm{a})$ & $5.31 \pm 0.57(\mathrm{a})$ & $33.8 \pm 0.8(\mathrm{~b})$ & $70.5 \pm 1.0(\mathrm{a})$ & $1.11 \pm 0.77(\mathrm{~b})$ & $1.70 \pm 0.25(\mathrm{c})$ \\
\hline
\end{tabular}

Means \pm SD followed by different letters in parentheses are significantly different at $5 \%$ level by Duncan's Multiple Range Test

Liquefaction methods: $A 2 \%(\mathrm{v} / \mathrm{w})$ lactic acid was used as liquefaction agent, $B 0.2 \%(\mathrm{v} / \mathrm{w})$ Termamyl was added at $85^{\circ} \mathrm{C}$ and heated to $121^{\circ} \mathrm{C}$ for 50 min during liquefaction, $C 0.1 \%(\mathrm{v} / \mathrm{w})$ Termamyl was added at $85^{\circ} \mathrm{C}$ and heated to $12^{\circ} \mathrm{C}$ for $50 \mathrm{~min}$, then another $0.1 \%(\mathrm{v} / \mathrm{w})$

Termamyl was boosted when temperature was cooled down to $90^{\circ} \mathrm{C}$ during liquefaction, $D 2 \%(\mathrm{v} / \mathrm{w})$ lactic acid was used as liquefaction agent, $E$ $0.2 \%(\mathrm{v} / \mathrm{w})$ Termamyl was added at $85^{\circ} \mathrm{C}$ and heated to $121^{\circ} \mathrm{C}$ for $50 \mathrm{~min}, F 0.1 \%\left(\mathrm{v} / \mathrm{w}\right.$ ) Termamyl was added at $85^{\circ} \mathrm{C}$ and heated

to $12^{\circ} \mathrm{C}$ for $50 \mathrm{~min}$, then another $0.1 \%(\mathrm{v} / \mathrm{w})$ Termamyl was boosted when temperature was cooled down to $90^{\circ} \mathrm{C}$ during liquefaction

${ }^{\mathrm{a}} \mathrm{Specific}$ viscosity

${ }^{\mathrm{b}} 2 \%(\mathrm{v} / \mathrm{w})$ liquefied rice powder culture was used as inocula

${ }^{\mathrm{c}} 120$-g bread koji was used as inocula 
Table 2 Effect of inoculum amounts on lag phase during solid-state fermentation of Monascus purpureus

\begin{tabular}{ll}
\hline Inoculum ratio $(\%, \mathrm{v} / \mathrm{w})$ & Lag phase $(\mathrm{h})$ \\
\hline 0.7 & $25.70 \pm 0.26(\mathrm{a})$ \\
1.0 & $20.80 \pm 0.53(\mathrm{~b})$ \\
2.0 & $16.50 \pm 0.38(\mathrm{c})$ \\
4.0 & $16.00 \pm 0.30(\mathrm{c})$ \\
\hline
\end{tabular}

Cell concentration of the liquid inocula was $4.78 \%$ (w/v); means \pm SD followed by different letters in parentheses are significantly different at 5\% level by Duncan's Multiple Range Test

filamentous red mold culture. In eliminating this effect, different liquefaction methods were compared based on the final cell concentration, $\mathrm{pH}$ value, total acidity, residual sugars, end point volume, and specific viscosity.

Results were shown in Table 1, which concluded that preparation based on method $\mathrm{F}$ would provide the best harvest of $M$. purpureus $(4.86 \pm 0.27 \%$, w/v) after a 5 -day period and was adopted, hereafter, in this research as inocula.

Amounts of liquid inocula on lag phase

Solid-state fermentation is difficult to control, especially on the aspect of prevention of microbial contamination from the surroundings. The growth rate of Monascus sp. is much slower than that of other two fungi, Aspergillus sp. and Rhizopus sp., which are commonly found as contaminant strains in red mold rice fermentation. For providing an environment for $M$. purpureus to prevail over the other competitors, the optimal quantities of liquid inocula were tested by comparing the lag phase of the solid-state fermentation. Increase of Monascus inocula may have the

Table 3 The influence of soaking time on koji moisture content

\begin{tabular}{ll}
\hline Soaking time $^{\mathrm{a}}$ & Moisture content (\%) \\
\hline $0 \mathrm{~s}$ & $30.00 \pm 0.00(\mathrm{a})$ \\
$10 \mathrm{~s}$ & $40.30 \pm 0.58(\mathrm{~b})$ \\
$30 \mathrm{~s}$ & $44.60 \pm 0.46(\mathrm{c})$ \\
$60 \mathrm{~s}$ & $47.20 \pm 0.40(\mathrm{~d})$ \\
$2 \mathrm{~min}$ & $48.70 \pm 0.21(\mathrm{e})$ \\
$4 \mathrm{~min}$ & $49.80 \pm 0.35(\mathrm{f})$ \\
$6 \mathrm{~min}$ & $50.30 \pm 0.31(\mathrm{gf})$ \\
$10 \mathrm{~min}$ & $51.00 \pm 0.15(\mathrm{gh})$ \\
$15 \mathrm{~min}$ & $51.40 \pm 0.30(\mathrm{~h})$ \\
$20 \mathrm{~min}$ & $51.60 \pm 0.17(\mathrm{~h})$ \\
$25 \mathrm{~min}$ & $51.70 \pm 0.12(\mathrm{~h})$ \\
\hline
\end{tabular}

Means \pm SD followed by different letters in parentheses are significantly different at $5 \%$ level by Duncan's Multiple Range Test

${ }^{a}$ Soaking condition was: 1-kg koji (moisture content ca 30\%) was soaked in a 20-1 water bath to simulate koji soaking by traditional method effect of predominating the growth under a semi-open circumstance for solid state fermentation. Lag phase was determined based on the time for the inoculated cooked rice to raise its central temperature up to $38^{\circ} \mathrm{C}$. Table 2 showed that the inocula at $2.0 \% \mathrm{v} / \mathrm{w}$ would provide an acceptable lag phase of $16 \mathrm{~h}$.

Water sorption capacity of red mold rice

Moisture content of the rice koji decreased dramatically during solid-state fermentation due to aeration. This would cause drying and hardening of the rice, which, in turn, impede penetration of fungal filaments into rice grain, and thus, hamper the growth of M. purpureus. As indicated in Fig. 1, the traditional method for making red mold rice involves at least three times of water soaking during fermentation to maintain the moisture content of the rice grains. Therefore, it is necessary to decide water sorption capacity of the cooked rice grain when developing a wateradding system in the solid-state fermentor. Table 3 revealed that a soaking time of 6 min would reach a moisture content of around $50 \%$. Extending soaking time to longer than $6 \mathrm{~min}$ did not increase moisture content significantly. Understanding of this characteristic would help in developing a suitable water-adding system to keep the rice koji at the optimal moisture content for fermentation.

Water adding timing on red pigment development

Rice koji has to be taken out from the fermentation room 3 days after inoculation and soaked in water to keep the moisture content at a certain level. This is the most laborintensive step in the traditional method. However, when a large-scale koji maker is in use, aeration and the fermentation heat generated from growth speed up the loss of moisture content. Therefore, the timing for adding water to make up the moisture content for further fermentation should be earlier than that of the traditional method.

Based on the analysis of moisture contents of rice koji during fermentation at the time of water adding and the relationship between water adding time and final red pigment production, it was decided according to Fig. 3 that the 36th hour after inoculation was the optimal water adding time when using the modified large scale koji maker.

Effects of different methods of water adding

Three different prototypes for effective water sorption of rice koji were tested with the Nagata koji maker, namely, atomized water spray, direct water pouring, and water curtain, respectively. A spray nozzle was applied for atomized water spray, while a water hose was used, instead, 


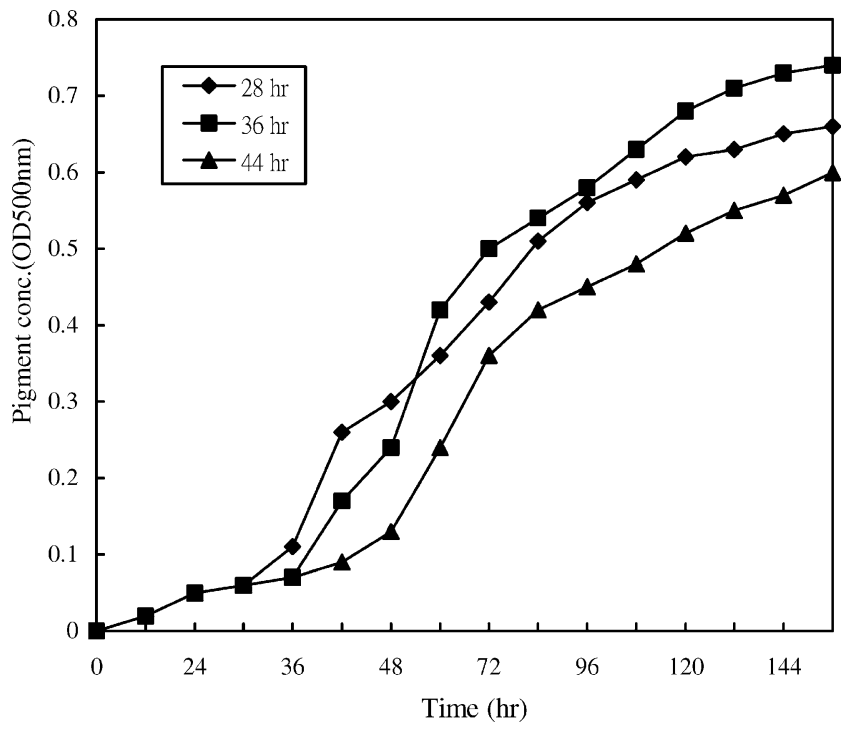

Fig. 3 Effect of water adding time on production of red mold rice pigment

for direct water pouring. However, a self-designed overflow device was employed to provide water curtain when needed. The apparatus consists of a rectangular water container. When water is overfilled, overflow becomes a thin curtain falling down directly to the koji bed. Results of these tests would be used later to modify the original Nagata koji maker as an invention. Water was added at the 36th hour after fermentation began; moisture content of red mold rice koji sampled from different spots of the rotary bed were analyzed. Data shown in Table 4 suggested that the method of water curtain was the most effective way for water adding. Atomized water by spray nozzle only provided atomized water on the surface of koji, not into the bed. Direct water pouring only provided some spots for water to flow through the bed. However, water curtain could provide an even water fall through the whole koji bed and resulted in better water sorption of the koji. However, water collecting and recycling devices under the perforated bed were also needed when using this method as water was added in great excess of the amount absorbed by the koji.
Table 5 Influence of agitation on white rice koji, red pigment production and broken rice percentages

\begin{tabular}{llll}
\hline Agitation $^{\mathrm{a}}$ & $\begin{array}{l}\text { White rice koji } \\
(\%)\end{array}$ & $\begin{array}{l}\text { Red pigment } \\
\left(\mathrm{OD}_{500 \mathrm{~nm}}\right)\end{array}$ & $\begin{array}{l}\text { Broken rice } \\
\text { koji }(\%)\end{array}$ \\
\hline A & $3.70 \pm 0.28(\mathrm{a})$ & $0.85 \pm 0.07(\mathrm{a})$ & $29.10 \pm 0.42(\mathrm{a})$ \\
$\mathrm{B}$ & $3.10 \pm 0.21(\mathrm{a})$ & $0.90 \pm 0.02(\mathrm{a})$ & $30.10 \pm 0.35(\mathrm{a})$ \\
$\mathrm{C}$ & $0.90 \pm 0.14(\mathrm{~b})$ & $1.01 \pm 0.14(\mathrm{a})$ & $31.20 \pm 0.77(\mathrm{a})$ \\
\hline
\end{tabular}

Means \pm SD followed by different letters in parentheses are significantly different at $5 \%$ level by Duncan's Multiple Range Test

${ }^{\mathrm{a}} A$ Mixing of koji bed co-currently three rounds right after feed in, $B$ mixing of koji bed co-currently three rounds $12 \mathrm{~h}$ after feed in, $C$ mixing of koji bed counter-currently three rounds $12 \mathrm{~h}$ after feed in

In addition, this water recycling system functioned, recycling the wash-off fungal filaments back to the koji.

Agitation for reducing white rice koji percentage

White rice koji is the rice grain that is not fermented by $M$. purpureus and is regarded as a major defect of red mold rice production. The most possible reasons for this defect are block formation due to cooked rice agglomeration and loss of moisture. The latter results in hardening of the cooked rice, and it becomes too hard for red mold growth. Influences of factors causing white rice koji could be reduced by improved agitation timing and method. A perforated paddle-type blender capable of both co- and counter-current agitation relative to the direction of bed rotation was applied, which was also a major part of this research. Table 5 showed the effects of various agitations and timings on the reduction of the percentage of white rice koji. Results suggested that one round of bed rotation with counter-current agitation at the 12th hour after fermentation began could harvest red mold rice with higher red pigment content and less percentage of white rice koji as shown in Fig. 4.

Temperature control at the final stage of fermentation

Temperature has been found as the important factor influencing productions of red pigment and other secondary metab-

Table 4 Effect of different methods of water addition to the moisture content of red mold rice koji during solid state fermentation

\begin{tabular}{|c|c|c|c|c|}
\hline \multirow[t]{2}{*}{ Water adding methods } & \multirow[t]{2}{*}{ Original moisture content $(\%)$} & \multicolumn{3}{|c|}{ Moisture content (\%) } \\
\hline & & 1 st round ${ }^{\mathrm{a}}$ & 2nd round & 3 rd round \\
\hline Atomized water & $30.1 \pm 1.2(\mathrm{aA})$ & $37.7 \pm 1.9(\mathrm{cB})$ & $41.6 \pm 2.6(\mathrm{cC})$ & $45.1 \pm 2.3(\mathrm{bD})$ \\
\hline Direct water pouring & $30.0 \pm 1.2(\mathrm{aD})$ & $39.8 \pm 1.6(\mathrm{bC})$ & $46.5 \pm 1.6(\mathrm{bB})$ & $50.0 \pm 1.3(\mathrm{aA})$ \\
\hline Water curtain & $30.3 \pm 1.0(\mathrm{aC})$ & $46.1 \pm 1.7(\mathrm{aB})$ & $51.2 \pm 2.2(\mathrm{aA})$ & $51.6 \pm 2.5(\mathrm{aA})$ \\
\hline
\end{tabular}

Means \pm SD followed by different uppercases in the same row and different lowercases in the same column, in parentheses, are significantly different at 5\% level by Duncan's Multiple Range Test

${ }^{a}$ Rotating time per round is about $12 \mathrm{~min}$ 

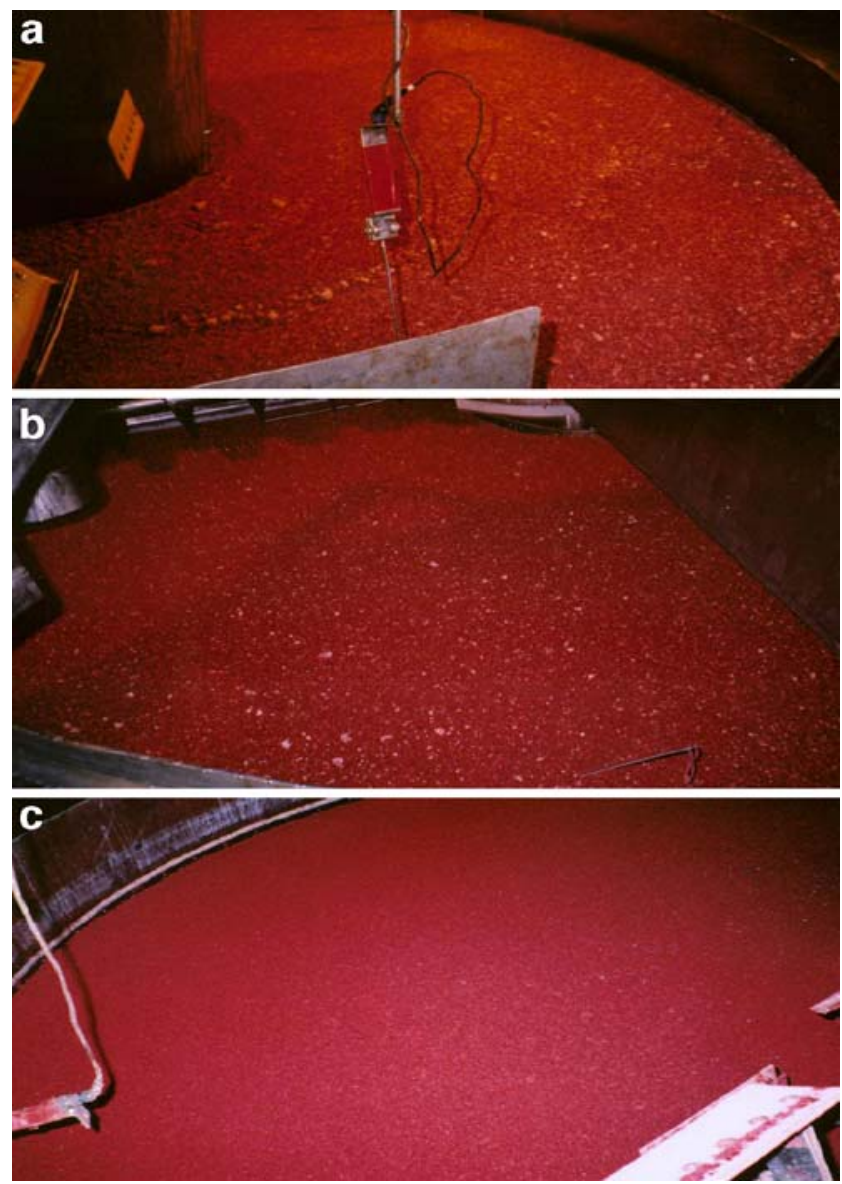

Fig. 4 Reducing white koji using different ways of agitation: a mixing of koji bed co-currently three rounds right after feed in, $\mathbf{b}$ mixing of koji bed co-currently three rounds $12 \mathrm{~h}$ after feed in, $\mathbf{c}$ mixing of koji bed counter-currently three rounds $12 \mathrm{~h}$ after feed in

olites, such as monacolin $\mathrm{K}$ and citrinin. Literature shows that temperatures at the range of $25-35^{\circ} \mathrm{C}$ are good for productions of red pigment and monacolin $\mathrm{K}$ by $M$. purpureus (Endo 1979). However, in the solid-state fermentation of $M$. purpureus using a large scale koji maker, temperature was kept at $37-38^{\circ} \mathrm{C}$ for effectively facilitating reproduction and growth. In increasing red pigment and monacolin $\mathrm{K}$ in the product, temperature at the final stage of fermentation has to be kept at an optimum. Results were listed in Table 6 . When temperatures at the 86th hour till the end of fermentation were maintained at 26,30 , and $34^{\circ} \mathrm{C}$, respectively, there was not much significant difference in the productions of red pigment, monacolin $\mathrm{K}$, and citrinin. From the energy point of view, $34^{\circ} \mathrm{C}$ was accepted as the temperature wherein there is no need in lowering the temperature too much at the final stage.

\section{Discussion}

In the traditional process, agitation with hands is needed in flipping over the bottom part of rice koji and removing fermentation heat. Each tray is taken out many times from the fermentation room and soaked in water to maintain the proper moisture content of rice koji. So it is easy to control the temperature and moisture content during fermentation.

However, the traditional method needs large space, high labor costs for koji agitation by hands and water soaking, and a long process time. At the same time, red mold rice is easily contaminated by the open environmental factors, which always results in inconsistent and unsatisfactory quality.

Literature survey on red mold rice production in a closed environment using a koji maker shows no successful cases. The result of this study was attributed to the difficulties of water addition and fermentation heat removal.

Reports on microbial strains used in red mold rice production and functional properties of metabolites were easily found. Most of these works focused on the production capacities of monacolin, pigment, GABA, etc., and their applications as dietary supplements in healthy foods (Endo 1979, 1980; Hawksworth and Pitt 1983, Lee et al. 2005, Wang et al. 2005). So it is a very important issue to develop the process for mass production of red mold rice.

Nagata type koji maker was originally designed to making koji with Aspergillus sp. The physiological and morphological characteristics of Aspergillus sp. were different from Monascus sp., especially on the aspects of moisture need and temperature rising speed of rice koji during solid-state fermentation.

We studied the modification for mass production of red mold rice in a more hygienic and controllable condition with mechanized koji-making facilities in this research. Controls of rice koji moisture content and fermentation temperature, and hence, modification of the koji maker, are

Table 6 Effect of temperature control at the final stage of fermentations on metabolites productions

\begin{tabular}{lllll}
\hline Temperature $^{\mathrm{a}}\left({ }^{\circ} \mathrm{C}\right)$ & Glucoamylase (units) & $\begin{array}{l}\text { Pigment } \\
\left(\mathrm{OD}_{500 \mathrm{~nm}}\right)\end{array}$ & Monacolin K (ppm) & \\
\hline 34 & $135.0 \pm 18.2(\mathrm{a})$ & $0.91 \pm 0.27(\mathrm{a})$ & $46.5 \pm 9.5(\mathrm{a})$ & $616.5 \pm 10.8(\mathrm{a})$ \\
30 & $78.0 \pm 11.4(\mathrm{ab})$ & $0.87 \pm 0.18(\mathrm{a})$ & $53.0 \pm 20.3(\mathrm{a})$ & $467.0 \pm 85.1(\mathrm{a})$ \\
26 & $48.5 \pm 7.0(\mathrm{~b})$ & $0.75 \pm 0.50(\mathrm{a})$ & $53.5 \pm 5.7(\mathrm{a})$ & $331.5 \pm 263.6(\mathrm{a})$
\end{tabular}

Means \pm SD ( $n=3$ ) followed by different letters in parentheses are significantly different at $5 \%$ level by Duncan's Multiple Range Test

${ }^{a}$ Temperature was lowered at the 86 th hour to $26,30,34^{\circ} \mathrm{C}$, respectively, in $4 \mathrm{~h}$ and maintained until the end of fermentation 
definitely the cores of this research. The ultimate goals are to develop an optimal process for red mold rice mass production with high and consistent quality and low cost to meet the increasing market demand of healthy foods.

In this work, we focused mainly on the mass production of red mold rice using a large scale koji maker which we modified from a commercial one. Compared to the traditional method which needs longer time, more workforce and production space, we had successfully reduced process time, workforce, and space in a compact solid state fermentor. The results indicated that the modifications were promising and potentially useful for industrial application.

Red mold rice production using the modified Nagata type koji maker was concluded feasible with appropriate hardware modifications on water-adding and agitation systems and software preprogramming for optimal temperature and humidity conditions from this research. Further investigation was suggested to integrate with a programmable logic controller/personal computer (PLC/PC)-based on-line man-machine interface (MMI) control system for more automatic and accurate temperature, moisture content, and timing control.

Acknowledgements This research was granted by the National Science Council, Taiwan (NSC 92-2214-E-020-002). Special thanks are due to the Taiwan Tobacco and Liquor Corporation (Pingtung, Taiwan) for providing the equipment and support.

\section{References}

Aniya Y, Ohtani I, Higa T, Miyagi C, Gibo H, Shimabukuro M, Nakanishi H, Taira J (2000) Dimerumic acid as an antioxidant of the mold: Monascus anka. Free Radi Biol Medic 28:999-1004

Anonymous (1994) Analysis of distilled liquors. Taiwan Wine Research Institute, Taipei, Taiwan (in Chinese)

Bau CA (1996) Physiological properties of Monascus. Journal of Chinese Fermentation 2:11-20 (in Chinese)

Blanc PJ, Laussac JP, Le Bars J, Le Bars P, Loret MO, Pareilleux A, Prome D, Santerre AL, Goma G (1995) Characterization of monascidin A from Monascus as citrinin. Inter J Food Microbiol 27:201-203

Endo A (1979) Monacolin K: a new hypocholesterolemic agent produced by a Monascus species. J Antibiot 32:852-854

Endo A (1980) Monacolin K: a new hypocholesterolemic agent that specifically inhibits 3-hydroxy-3-methyl-glutaryl coenzyme A reductase inhibitors. J Antibiot 33:334-336

Hawksworth DL, Pitt JI (1983) A new taxonomy for Monascus species based on cultural and microscopic characters. Aust J Bot 31:51-61

Hsieh YT, Pan TM (2002) Establishment of analytical methods for secondary metabolites of the market sold red mold rice. Journal of the Taiwan Biomass Energy Society 21:63-71 (in Chinese)

Huang HC (1985) Review and perspective of Monascus studies. Seminars Proceedings of Biological Research Center, National Science Council, Taipei, Taiwan 12:109-124 (in Chinese)

Kao H (1997) Applications of red mold rice in traditional Chinese foods and nutroceutical diets. Journal of Chinese Fermentation 6:12-14 (in Chinese)

Lee CL, Tsai TY, Wang JJ, Pan TM (2005) In vivo hypolipidemic effects and safety of low dosage monascus powder in a hamster model of hyperlipidemia, Appl Microbiol Biotechnol (online)

Lin TF (1982a) Red mold rice production with automatic aeration, temperature control, and thicker bed depth. Special Issue of Wine Making Technol 4:152-153 (in Chinese)

Lin TF (1982b) Study on the modified production of red mold rice. Annual Report of Taiwan Wine Research Institute, Taipei, Taiwan 159-172 (in Chinese)

Lin TF (1987) Application of programmable controller in koji making. Annual Report of Taiwan Wine Research Institute, Taipei, Taiwan 165-178 (in Chinese)

Lizuka H, Lin CF (1980) On the genus Monascus of Asia and its specific characteristics. Adv Biotechnol 2:555-561

$\mathrm{Su}$ YC (2001) The Magic Monascus sp. Yuan-Chi Jai, Taipei, Taiwan (in Chinese)

Su YC, Chen WL, Fan HY, Weng HC, Wang WH (1970) Microbial study of Monascus. J Chin Agric Chem Soc 8:46-54 (in Chinese)

Su YC, Wang JJ, Lin TT, Pan TM (2003) Study of the production of the secondary metabolites $\gamma$-aminobutyric acid and monacolin $\mathrm{K}$ by fermentation of Monascus. J Ind Microbiol Biotech 30: $41-46$

Wang JJ, Shieh MJ, Kuo SL, Lee CL, Pan TM (2005) Effect of red mold rice on antifatigue and exercise-related changes in lipid peroxidation in endurance exercise. Appl Microbiol Biotechnol $70: 247-253$ 